\title{
ANPHLAC y los diálogos entre Brasil y las Américas. Cartografías y experiencias de un diálogo situado
}

\author{
Patricia Funes*
}

Originalidad, profesionalismo y excelencia son, a mi juicio, cualidades que describen esos diálogos entre Brasil y las Américas impulsados por ANPHLAC (Associação Nacional de Pesquisadores e Professores de História das Américas) en estas casi dos décadas de tránsito.

Si los organizadores de esta, a mi juicio, excelente iniciativa buscaron una analítica "externa" para este artículo, advierto que se desilusionarán un poco. Apelaré a la idea gadameriana de "hermenéutica situada". El carácter situado implica "admitir el compromiso que de hecho opera en toda comprensión", reconociendo que "la comprensión no es nunca un comportamiento subjetivo respecto a un 'objeto' dado, sino que pertenece a la historia efectual, esto es, al ser de lo que se comprende." la pauta de escritura y de eventuales lecturas, paso a mis argumentos.

No conozco otra asociación de historiadores de un país latinoamericano que se haya fijado como objetivo y decurso, la investigación, la promoción de recursos humanos, el intercambio académico entre las universidades de todo su territorio y con colegas del exterior, referidos a las Américas. Una Asociación recortada en sus perímetros exceptuando aquellos colegas que trabajan exclusivamente sobre la historia de su propio país, que -en el caso de Brasil- cuenta con otras asociaciones, representatividades y encuentros.

Un planteo, entonces, tan original como desafiante. La propuesta perseguía la creación de un espacio convergente para aquellos investigadores y docentes universitarios que no se han abocado a la siempre demandante historia de su país, para pensar la región como colectivo con sus especificidades y notas características. Y con los sellos identitarios de sus pertenencias institucionales y nacionales. Esto también otorga significados y miradas originales a ANPHLAC. No lo dicen sus postulados pero considero que existe ese sello, esa mirada. Y es muy productiva esa interacción con esas miradas.

\footnotetext{
* Professora da Universidade de Buenos Aires (UBA/CONICET). E-mail: patfunes@ gmail.com

${ }^{1}$ Gadamer, Hans-Georg, Verdad y método, Salamanca, Ediciones Sígueme, 2007, pp. 10, 13 y 14. 
En cada uno de nuestros países (quizá a excepción de México y no tan paradójicamente los EEUU) hubiéramos suscripto la necesidad de fortalecer (en muchos casos de crear casi ex nihilo) los estudios latinoamericanos en nuestras universidades y centros de investigación al regreso del orden democrático, que animó la creación de ANPHLAC. De hecho, desde el primer Encuentro al que asistí como expositora, la experiencia fue determinante e identificadora. Teníamos muchos temas y problemas comunes con un Brasil muy lejano a nuestras experiencias historiográficas. Apenas si conocíamos la producción no sólo de latinoamericanistas brasileños sino de los especialistas en historia de Brasil de las universidades de ese cercano en distancias y lejano en conocimientos (a excepción de la música, que selló mi generación).

Esa originalidad tiene otras marcas: las inherencias de la Historia como campo de conocimiento. Lo sabemos, la Historia nos viene desde los griegos y se institucionalizó profesional y disciplinariamente en el siglo XIX. No es casual que por entonces se haya definido su musa inspiradora: Clío. ¿Qué vemos en esa representación? Un conjunto de símbolos fundacionales: en muchos casos un pergamino en una de sus manos prodigiosas, que alude a la relación entre historia/escritura/documentos. Frecuentemente porta una clepsidra, suerte de reloj que no era de arena sino de agua. Es de agua porque no necesita del sol, es decir, el reloj funciona también en las noches, ininterrumpidamente. La clepsidra invoca mitológicamente el amparo de Cronos y el imperio de la historia de pautar temporalmente los pasados evitando los riesgos anacrónicos y las seducciones ucrónicas. La clepsidra es reveladora, ya que ese reloj de agua refiere a la idea de que la parte de abajo del reloj le roba el tiempo a la parte de arriba. En algún sentido los historiadores somos cleptómanos del pasado para atraparlo convertido en explicaciones y comprensiones, sin justificarlo. Intentando entenderlo fundadamente, con esos documentos sujetos a la interpretación, pero que están allí, incontrastables.

Clío también tiene una trompeta muy protagónica. Se la llama "la proclamadora" y etimológicamente remite a "ponderar", “alabar", “ensalzar", verbos fuertes, épicos, con los que probablemente no nos identifiquemos. La Clío institucionalizada del siglo XIX ensalzaba y ponderaba al Estado-Nación. Clío, entonces, es una figura que tiene que ver con las trompetas, las mayúsculas, los héroes y los siempre celosos perímetros estatal-nacionales. 
Sabemos también de las renovaciones de la Historia en el siglo XX, desde la Escuela de los Annales hasta hoy, que han resituado esos símbolos. El más importante: la ubicación del historiador con sus preguntas desde su más arraigado e inclaudicable presente.

Esta digresión, en principio caprichosa, guarda relación con las temporalidades de nuestro propio campo de estudios en y sobre América Latina. Los años sesenta y setenta del siglo pasado fueron épocas de latinoamericaneidades alentadas por las distintas vertientes del dependentismo cruzadas por la profesionalización del campo sociológico (desde Gino Germani a José Medina Echevarría, para poner dos figuras emblemáticas) o desde Raúl Prebisch y la CEPAL o el ILPES a Celso Furtado, en el campo de la economía política. Y si la épica del Estado Nación anegaba los símbolos de la Clío del siglo XIX, pues en América Latina por esos años, fue la revolución/reforma y el antiimperialismo la épica dominante.

Esos senderos impulsaron algunas derivas en el campo de la historia económica (sobre todo colonial), que en ocasiones devenía sólo la "contrastación fáctica" del modoproduccionismo o el circulacionismo, acalorado debate en boga por entonces. Aún así, la Historia permaneció apegada a los contornos nacionales azuzada por marcos teóricos que inspiraron tanto investigaciones luminosas y explicativas cuanto reproducciones algo mecánicas de esos marcos que -en oportunidades- actuaron más como corsets que como caminos creativos para pensarnos con nuestras temporalidades, nuestras comprensiones y nuestras identidades y memorias. Aunque pueda parecer un oxímoron, se puede hacer historia sin historicidad, es decir, sin esa relación continuidad-cambio, diástole y sístole del corazón del oficio del historiador.

También sabemos que la reflexión sobre América Latina comporta no pocas dificultades. En principio la propia existencia del objeto es problemática. Desde la ensayística, la historia o las ciencias sociales ha habido tenaces defensores de la idea de historias comunes -incluso, de destinos- tan enfáticos como los detractores de la misma. En cualquier caso los análisis recorren un rango interpretativo que va desde esencialismos identitarios (regionales, nacionales o étnicos) hasta la aplicación mecánica de categorías teóricas clásicas (positivismo, marxismo, funcionalismo, posmodernismo). La tensión entre particularismo y universalismo se cuela en cada aproximación, constituyéndose en un problema recurrente y siempre visitado 
Las dictaduras institucionales de las Fuerzas Armadas en el Cono Sur, menos preocupadas por esas sutilezas, consideraron a América Latina como "subversiva". Asunto que fue sagaz y tempranamente advertido por la Profesora Philomena Gebran en el primer número de la Revista Eletrônica da ANPHLAC y que muchos años después he corroborado como parte de mis investigaciones a partir de la documentación "secreta, confidencial y reservada" de los archivos de inteligencia de mi país.

La historia de América Latina era "problemática" en el sentido negativo de la palabra, cuando no censurada explícitamente. En cada país con sus modalidades. Bien es sabido que el elam desarrollista de la dictadura en Brasil en algunos de sus tramos, amplió los estudios de postgrado, asunto que no ocurrió en Chile, mucho menos en Argentina y Uruguay. Sin embargo, dedicarse a la historia de una región que se desdibujaba a fuerza de violencias y censuras (incluso de muertes y desapariciones) no fue muy alentador para nuestro campo de estudios. Todo lo contrario y va de suyo la explicación.

La academia mexicana, en la que muchos investigadores argentinos, chilenos y uruguayos encontraron generosos espacios para los siempre desgarradores exilios, fue un centro gravitacional de trabajos señeros sobre de la región. Una región descubierta "desde afuera" de los contornos nacionales. No era la primera vez. Hay una larga genealogía intelectual latinoamericana de descubrimientos de la región durante los siglos XIX y XX que se dibuja desde el "afuera": desde el viaje inciático a Europa o desde los exilios políticos, que bien merecería un trabajo más sistemático de reconstrucción.

Territorio de los "pre" o los "sub" hoy los estudios latinoamericanos desde América Latina están más emancipados. Y ANPHLAC es una contribución imprescindible en esa independencia.

Original, dije, y voy a fundamentar la aseveración con un dato más. Recuperadas las democracias políticas, también se habló desde los centros de poder hegemónicos de El fin de la historia, incluso del último hombre (afortunadamente no se hablaba de la última mujer ya que aún los derechos de cuarta generación no estaban tan en boga). La traducción del libro de Francis Fukuyama al español fue en el año 1992. Ese año se conmemoraba el Quinto Centenario de.... es controversial, simplificando: de la llegada de Colón a esta parte del mundo, para no desviarnos del argumento. En "esta 
parte del mundo", sumada a España, se multiplicaron los Congresos, las publicaciones y las polémicas. Y cuando digo la región incluyo a Brasil (recuerdo un enorme Congreso en San Pablo: América 92: Raízes e trajectórias). La historia no había terminado en estas latitudes, quizá recomenzaba.

Sin embargo, eran épocas de dominancias individualistas, de lógicas mercadocéntricas, de colonización de cierta jerga económico-gerencial sobre las humanidades y sus instituciones. También, momentos de intemperie de ideas.

Justamente por ese año 1992, un conjunto de historiadores brasileños, probablemente de los márgenes de sus instituciones, se reunían, "contra viento y marea", para formar la antesala de lo que hoy es ANPHLAC, quizá una forma de resistencia frente a esas intemperies. A mi juicio, esto también es un movimiento original de esa terca vocación: reunir voluntades, la historia como disciplina y la región como brújula. Esta vez sin exilios ni afueras. Una originalidad que se mostró muy productiva y muy creadora.

En estos años en los que he participado de varios encuentros de ANPHLAC, de conocer a muchos de sus investigadores y sus respectivas investigaciones, he constatado la sólida profesionalización de los estudios sobre América Latina en la academia brasileña. También, los análisis dialógicos que dan vuelta el mapa de la región como en el cuadro de Torres García en la consideración de las "miradas imperiales", tan alentadas por la Profesora Mary Junqueira.

Muchas de esas investigaciones fueron avances de becas iniciales de investigación que se convirtieron en innovadoras tesis doctorales, posteriormente publicadas. Todas instancias sometidas a los más altos estándares de evaluación y acreditación. Ese diálogo profesionalizado, entiendo, también es destacable. Diálogo no sólo temático y analítico sino acerca del "cómo" institucional. Proviniendo de un país en el que los postgrados en Historia tenían mucho menos (casi ningún) desarrollo hace tres lustros y que recién en los últimos años se han fortalecido a escala nacional, no dejaba de ser un aprendizaje de profesionalización.

Esa profesionalización de ANPHLAC no significa solemnidades ni estereotipos, sino prácticas abiertas al diálogo regional, sensible a los estímulos de las ciencias sociales, de la literatura, del cine, de la fotografía, de la memoria, de las ideas. ANPHLAC promueve un lugar profesional "conversador con el mundo" dijera Jorge 
Luis Borges, desde un arraigo sin complejos, con las reglas del campo en su dimensión más genuina.

Si de profesionalización se trata, también es importante señalar la continuidad de los Encuentros de ANPHLAC (y en estas dos décadas hemos vivido tiempos difíciles), de la publicación sistemática de la Revista Eletrônica, de los boletines, los anales, la website y otras herramientas de Internet, instrumentos tan útiles para nuestro trabajo cotidiano en las aulas y en nuestras investigaciones. Registros imprescindibles de actualización bibliográfica, de adelantos de investigaciones, de reseñas sobre reservorios documentales, de recursos para la enseñanza, de debates.

Otro dato elocuente de esa profesionalización es la formación de recursos humanos en la ancha y polícroma geografía del Brasil y los conscientes y deliberados estímulos de la Asociación de apoyar esos investigadores en sus espacios institucionales en las distintas universidades del país. Uno podría decir que los Encuentros son una excelente lección de la geografía del Brasil. En ellos, he aprendido sustantivamente de las investigaciones de profesores senior de la Asociación: Maria Ligia Prado, Maria Helena Capelatto (muy conocida entre mis estudiantes por su libro sobre propaganda política durante el varguismo), Heloisa Jochims, el increíble Jaime de Almeida que puede encontrar reservorios documentales debajo de la tierra y compartirlos por el éter de Internet, de Philomena Gebran, y del recordado Carlos Bruit. Todos/s muy distintos en sus orientaciones, lo que habla de pluralidades sin ingenuidades.

Pero también he seguido las trayectorias de sus discípulos, algunos de ellos con los que he compartido otras instancias académicas (se recuerdan de ADHILAC?) como Paulo Martínez, Alberto Aggio y, por razones de su objeto de estudio y sus viajes a Buenos Aires, del querido y respetado José Luis Beired (que salió airoso de un emprendimiento tan complejo como el de una Breve História da Argentina). Y a Katia Gerab y a Tom Gil, y nuevas generaciones como Gabriela Pellegrino o Stella Maris Scatena, entre tantos otros (las enumeraciones suelen ser muy peligrosas por la eventual injusticia de las omisiones, ya mismo recuerdo a Lilia Medrano o a Julio Pimentel Pinto, mala idea la de enumerar). Espero con curiosidad ponerme al día con los jóvenes investigadores en el próximo Encuentro. Subrayo esa doble condición: sus sólidas investigaciones, que generan siempre curiosidades, planteos sugerentes y muy inteligentes fuentes de respaldo sumado a sus responsabilidades de gestión y 
organización en postgrados y centros de estudios de distintas universidades y en la Asociación como gestores y sostenedores de su continuidad.

Pero, la "sección áurea" de ANPHLAC son las ideas. En estos tiempos en que las ideas parecen haber regresado al Sur del Sur, ANPHLAC las viene trabajando sin espectacularidades pero con una solidez y una continuidad excepcionales a nivel regional.

Finalmente (los caracteres se me esfuman y es de mal carácter excederse en las páginas), resaltaría dos aspectos más de este diálogo de ANPHLAC con las Américas, que hacen a la excelencia y a esa "mirada", a ese "estilo" al que antes hice alusión. Por un lado, el compromiso de trabajo serio, responsable y creativo que ha dado sus frutos. Se advierte en la multiplicación, el crecimiento, el fortalecimiento de enfoques, temáticas, actores, temporalidades, la diversificación de "casos nacionales", el abordaje de nuevos soportes documentales (el cine, la fotografía, la pintura, la música), la historia del siglo XX, las miradas contrahegemónicas en la producción académica de los historiadores de ANPHLAC que adquieren visibilidad en sus Encuentros bienales.

Pero también hay otro costado que es memoria y es historia de la Historia de ANPHLAC. Ese compromiso también lo fue en la reconstrucción institucional postdictaduras, un compromiso regional cuando la historia de América Latina aún era "subversiva" para las rémoras de esos poderes y la construcción del campo de estudios sobre América Latina debía sortear esos presupuestos.

Y creo que allí ANPHLAC fue decisiva.

Hoy también sus inspiradores y referentes actúan en debates del campo de forma valiente, responsable y abrumadoramente fundamentada. Remito, por ejemplo, a la intervención de la Profesora Maria Ligia Prado acerca de la Guia Politicamente Incorreto da América Latina, réplica traducida varias veces al español en varios blogs, sites y listas de correo electrónico. Ese también es un diálogo y un aprendizaje, ya que el debate acerca de los usos (y abusos) del pasado, sobre todo pero no solamente desde los massmedia y sus corporaciones, es un debate muy actual en los tiempos que corren en la región.

Afortunados tiempos más de encuentros que de desencuentros.

Y la Profesora María Ligia Prado es, sin lugar a dudas, una de las referentes más importantes de la historiografía de Nuestra América. Su reciente reconocimiento como 
Profesora Emérita dice mucho en la USP y en las universidades brasileñas. En este caso estoy refiriendo a su proyección latinoamericana en estos diálogos profesionales y a la vez fraternos.

Me referí a un diálogo situado y releyendo estas notas advierto ese péndulo entre historia y biografía que atraviesa este texto. Ya decididamente biográfico con la cuota de profesión que tiene la biografía: Maria Ligia Prado es una mujer que hace de su indudable profesionalismo y sus convicciones, solidaridades. Nunca olvidaré su mensaje cuando la crisis de 2001 en mi país, cuando éste parecía diluirse, quebrarse como un espejo trizado sin contornos. Gracias María Ligia.

Final, final, para siempre recomenzar: he regresado de cada diálogo con ANPHLAC con más ideas, con más preguntas, con más inquietudes y con renovadas ganas de esta vocación obstinada, imprescindible y fascinante que es muchas horas, muchas dudas, muchos documentos, sobre ésta Nuestra América. Que nos sorprende, nos convoca y nos compromete.

Parabens, ANPHLAC! 